\section{Kidney \\ Blood Pressure Research}

\title{
IgA Nephropathy in Czech Patients - Are We Able Reliably Predict the Outcome?
}

\author{
Dita Maixnerova Michaela Neprasova $^{a} \quad$ Jelena Skibova ${ }^{b} \quad J a n a$ Mokrisova ${ }^{a}$ \\ Romana Rysava $^{a} \quad$ Jana Reiterova ${ }^{a}$ Eva Jancova ${ }^{a}$ Miroslav Mertac Josef Zadrazil ${ }^{d}$ \\ Eva Honsova ${ }^{\mathrm{e}}$ Vladimir Tesar ${ }^{\mathrm{a}}$ \\ aDepartment of Nephrology, General Teaching Hospital and $1^{\text {st }}$ Faculty of Medicine, Charles University; \\ ${ }^{b}$ Department of Statistic analysis, Institute of Clinical and Experimental Medicine, Prague; 'Department \\ of Nephrology, Faculty of Medicine, University of Hradec Kralove, Hradec Kralove; 'IIIrd Department \\ of Internal Medicine, Faculty of Medicine, Palacky University, Olomouc; 'Department of Pathology, \\ Institute of Clinical and Experimental Medicine, Prague, Czech Republic
}

\section{Key Words}

IgA nephropathy $\cdot$ Risk factors $\cdot$ ESRD $\cdot$ Prognosis

\begin{abstract}
Background/Aims: The aim of our study was to retrospectively analyse data of 520 Czech patients with IgA nephropathy (IgAN) and to specify the risk factors affecting renal survival of IgAN patients. Methods: Cox proportional hazards regression model was used to evaluate the effects of different variables on renal survival during a median follow up of six years. McNemar's test was used to analyse the progression of renal function according to Bartosik's formula. Results: In our retrospective analysis of 520 Czech IgAN patients Cox proportional hazards regression model with five variables [hypertension, sex, GFR, proteinuria, age] was used. Significant regression coefficient was found for GFR, hypertension and proteinuria. Using stepwise algorithm GFR ( $O R=3.09)$, hypertension $(O R=2.09)$ and proteinuria $(O R$ $=1.97$ ) were found as the most important factors for renal survival in our group of IgAN patients. Among patients with CKD 3 we found significantly better renal survival in patients with proteinuria < $1 \mathrm{~g} /$ day compared to patients with higher proteinuria. We did not find the significant difference between predicted progression of renal function due to Bartosik's formula and real progression of renal parametres assessed by GFR at the end of the follow up in our group of IgAN patients. Conclusion: Our retrospective study of 520 Czech IgAN patients confirmed GFR, hypertension and proteinuria as the most important factors affecting the prognosis of IgAN patients. We validated Toronto Bartosik's formula to predict prognosis of IgAN patients.
\end{abstract}




\section{Kidney \\ Blood Pressure Research}

\section{Introduction}

IgA nephropathy (IgAN) is one of the most common primary glomerulonephritides in young adults, leading to end stage renal disease in about $50 \%$ of patients within 30 years with the necessity of renal replacement therapy [1].

Around $40 \%$ of renal biopsies from native kidneys in the Czech Republic are performed in our Department of Nephrology (it is about 200 renal biopsies per year) and we have already published our experience with IgAN patients [2]. In this paper we present the retrospective analysis of IgAN patiens extended to other nephrology centers in the Czech Republic. In total, we assessed 520 IgAN patients with a median follow up of 6 years. We compared clinical data, risk factors affecting the prognosis of IgAN patients among Czech centers and all around the world.

We also evaluated the progression of renal function according to the Bartosik's formula [3] and we compared it with the real progression of renal function assessed by glomerular filtration rate (GFR) at the end of the follow up in our group of IgAN patients.

\section{Materials and Methods}

We retrospectively analysed the findings of 520 patients with histologically proven IgAN diagnosed in the Department of Nephrology of the First Faculty of Medicine, Charles University in Prague (192 patients) and in other Czech nephrology centers (328 patients) from January 2000 to December 2010. Due to apparent limitations of our previous study (relatively short median follow-up of four years, frequent selection of patients with more serious clinical manifestations such as proteinuria or renal insufficiency) [2] we focused on IgAN patients bioptied and followed in our center for longer period (the total median follow up of 6 years). We also addressed other Czech nephrology centers to achieve comprehensive knowledge of patients with IgAN in the Czech Republic. Written informed consent for participation in the study was obtained from all adults participants. We assessed clinical, demographic data, and the medical treatment of IgAN patients. The patients with the diagnosis of Henoch-Schonlein purpura, liver cirrhosis and other secondary etiologies of IgAN were not included in this study. Diagnosis of IgAN was established by renal biopsy. The details about histological diagnoses of renal biopsies have already been published [2, 4]. Written informed consent for renal biopsy and for use of clinical data in this analysis was obtained from all patients and the study was approved by the ethics committee of the General University Hospital in Prague (1443/11 S-IV).

The following clinical data and medical treatment were analysed (initial data at the time of renal biopsy and the data at the end of the follow-up): serum creatinine ( $\mu \mathrm{mol} / \mathrm{L}), \mathrm{GFR}\left[\mathrm{mL} / \mathrm{s} / 1.73 \mathrm{~m}^{2}\right.$, measured as creatinine clearance, we used 2 values (initial and final) to calculate slope of $\mathrm{CrCl}$ ], proteinuria $(\mathrm{g} / 24$ h), microscopic haematuria (positive or negative according to the urine sediment), arterial hypertension [according to the World Health Organization (WHO) criteria], antihypertensive therapy, immunosuppressive treatment (corticosteroids, cyclophosphamide, azathioprine, cyclosporine in Prague center and „yes" or „no" immunosuppression in other nephrology centers).

Definition of arterial hypertension (according to WHO criteria): defined as a repeatedly elevated blood pressure, a systolic pressure $\geq 140 \mathrm{mmHg}$ with a diastolic pressure $\geq 90 \mathrm{mmHg}$; or patients with normal blood pressure $<130 \mathrm{mmHg}$ (systolic) $/ 85 \mathrm{mmHg}$ (diastolic) and taking antihypertensive drugs.

All data were statistically analysed. The influence of different variables on renal survival was analysed by Kaplan-Meier survival curves and comparison was made by the log rank test. The variables affecting renal survival were done by Cox proportional hazards regression model. Multivariate analysis of renal survival with choosed variables was created by stepwise algorithm in Cox proportional model.

To compare clinical parameters among different centers two-sample t-test or chi-square test were used. The comparison with the prediction of the progression of renal function assessed according to Bartosik's formula [3] was evaluated using the analysis of the dependence in accordance with McNemar's test. All tests were two-sided ones with a $\mathrm{P}<0.05$ considered statistically significant. Statistical analyses were performed using BMDP Statistical Software, Release 8.1. 


\section{Kidney \\ Blood Pressure Research}

Table 1. Variables at baseline, mean \pm SD or number of patients (\%)

\begin{tabular}{lcccc}
\hline & $\begin{array}{c}\text { General Teaching } \\
\text { Hospital in Prague }\end{array}$ & Other centers & $\begin{array}{c}\text { Czech centers } \\
\text { in total }\end{array}$ & P value \\
\hline Presenting proteinuria - mean (g/d) & $2.48 \pm 3.01$ & $2.54 \pm 2.59$ & $2.51 \pm 2.86$ & $\mathrm{P}=0.82 \mathrm{NS}$ \\
Gender-males, number of patients (\%) & $222(67.7)$ & $136(70.8)$ & $358(68.8)$ & $\mathrm{P}=0.45 \mathrm{NS}$ \\
Presenting hypertension, number of patients (\%) & $192(58.7)$ & $113(59.2)$ & $305(58.9)$ & $\mathrm{P}=0.92 \mathrm{NS}$ \\
Age - mean (years) & $40.44 \pm 14.19$ & $35.79 \pm 14.39$ & $38.73 \pm 14.43$ & $\mathrm{P}<0.001$ \\
Presenting GFR (ml/s) & $1.20 \pm 0.68$ & $1.40 \pm 0.59$ & $1.28 \pm 0.66$ & $\mathrm{P}<0.001$ \\
S-Creatinine-mean $(\mu \mathrm{mol} / \mathrm{L})$ & $161.95 \pm 116.91$ & $123.90 \pm 63.28$ & $147.90 \pm 102.09$ & $\mathrm{P}<0.001$ \\
Immunossupression, number of patients $(\%)$ & $112(21.5)$ & $103(19.8)$ & $215(41.3)$ & \\
Total patients (number) & 192 & 328 & 520 & \\
\hline
\end{tabular}

Table 2. Cox proportional hazards regression model. $* \mathrm{P}<0,05$; *** $\mathrm{P}<0,001$

Table 3. Cox proportional model - stepwise algorithm

\begin{tabular}{lccc}
\hline Variable & Coefficient & $\begin{array}{c}\text { Standard } \\
\text { deviation }\end{array}$ & $\begin{array}{c}\text { Coefficient/ } \\
\text { S.E. }\end{array}$ \\
\hline Hypertension & 0.7415 & 0.3262 & $2.2734^{*}$ \\
Sex & 0.1404 & 0.2749 & $0.5107 \mathrm{NS}$ \\
Age & -0.2122 & 0.2999 & $-0.7075 \mathrm{NS}$ \\
Proteinuria & 0.6781 & 0.1757 & $3.8590^{* * *}$ \\
GFR & -1.1306 & 0.2025 & $-5.5839^{* * *}$ \\
\hline
\end{tabular}

\begin{tabular}{lcrcc}
\hline Variable & Coefficient & $\begin{array}{c}\text { Standard } \\
\text { deviation }\end{array}$ & $\begin{array}{c}\text { Coefficient/ } \\
\text { S.E. }\end{array}$ & $\begin{array}{c}\text { Exp(Coefficient) } \\
=\text { OR }\end{array}$ \\
\hline Hypertension & 0.7050 & 0.3232 & 2.1816 & 2.09 \\
Proteinuria & 0.6764 & 0.1726 & 3.9193 & 1.97 \\
GFR & -1.1315 & 0.2020 & -5.6014 & 3.09 \\
\hline
\end{tabular}

\section{Results}

We retrospectively analysed data of 520 patients with IgAN diagnosed between the years 2000 and 2010 with the median follow up of 6 years (children below 15 years were excluded from the study). The clinical data from first clinical presentation are depicted in Table 1 . We found significant differences in mean age, mean level of serum creatinine and mean GFR among General Teaching Hospital in Prague and other Czech nephrology centers. Other significant differences in gender, presenting hypertension and proteinuria among Czech nephrology centers were not noticed.

In our retrospective analysis of 520 Czech IgAN patients, we used Cox proportional hazards regression model (Table 2) with five variables (hypertension, sex, age, proteinuria, GFR) to study their effect on renal survival (time to end stage renal disease) in IgAN patients.

Significant regression coefficient was found for GFR, hypertension and proteinuria. Using stepwise algorithm (Table 3), GFR (OR = 3.09), hypertension (OR = 2.09) and proteinuria $(\mathrm{OR}=1.97)$ were found as the most important factors for renal survival in our group of IgAN patients. Patients with hypertension had 2.1 times higher risk of end stage renal disease compared to normotensive patients. Patients with proteinuria $>1 \mathrm{~g} / 24$ hours had 1.97 times higher risk of end stage renal disease compared to patients with proteinuria $\leq 1 \mathrm{~g} / 24$. The group of patients with renal insufficiency (CKD 2; GFR $1.49-1 \mathrm{ml} / \mathrm{s}$ ) had 3.1 higher risk of end stage renal disease compared to patients with CKD 1 and patients with normal renal parametres. The influence of sex and age was not confirmed.

The total 10-year actuarial renal survival was $77.1 \%$. We ascertained significant variability in renal survival among centers with 10-year actuarial survival of $64.5 \%$ in General Teaching Hospital in Prague and $88.3 \%$ in other Czech nephrology centers ( $\mathrm{P}<$ 0.001) (Figure 1).

We confirmed reduced renal survival in patients with renal insufficiency, arterial hypertension and proteinuria $>1 \mathrm{~g} /$ day (Figure 2, 3 and 4). Among patients with CKD 3 we 


\section{Kidney \\ Blood Pressure Research}

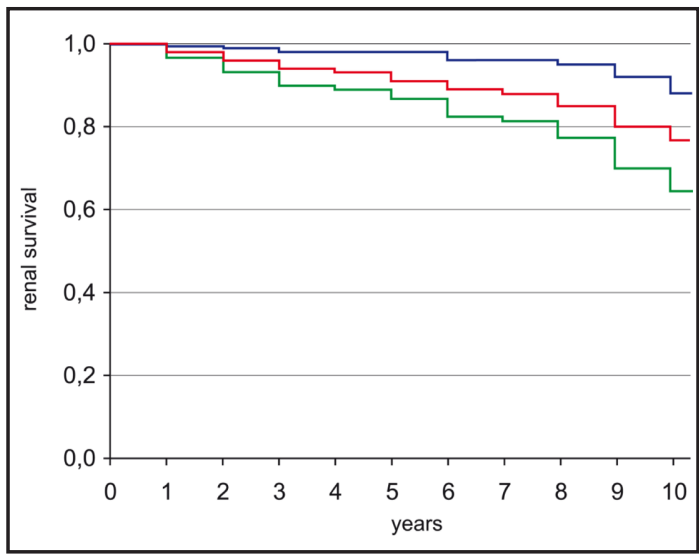

Fig. 1. The overall Kaplan-Meier actuarial renal survival in Czech patients with IgAN (red line, the 10year renal survival was $77.1 \%$ ). Renal survival of General Teaching Hospital in Prague (green line, the 10 -year renal survival was $64.5 \%$ ) vs other nephrological Czech centers (blue line, the 10-year renal survival was $88.3 \%$; Log rank test: $\mathrm{P}<0.001$ ).

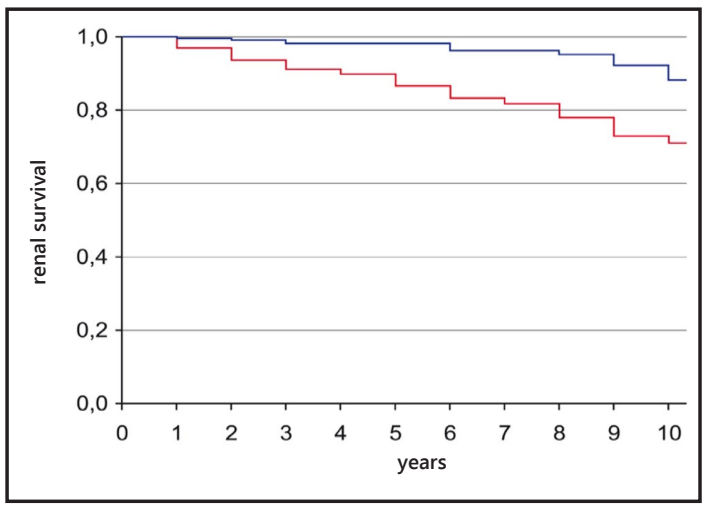

Fig. 3. Kaplan-Meier curves showing the survival probability according to arterial hypertension at presentation. Patients with arterial hypertension (red line, the 10-year renal survival was $71 \%$ ), patients without arterial hypertension (blue line, the 10 -year renal survival was $88 \%$ ); $\mathrm{P}<0.001$.

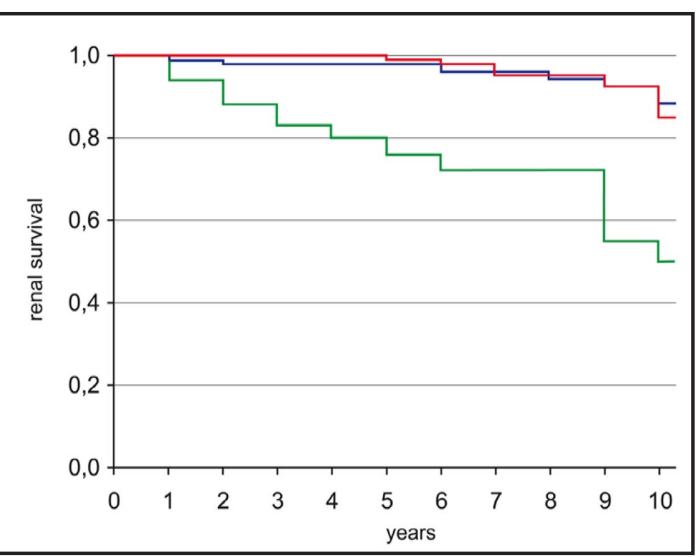

Fig. 2. Kaplan-Meier curves showing the survival probability according to input GFR. Patients with GFR $\geq 1.5 \mathrm{ml} / \mathrm{s}$ (blue line, the 10 -year renal survival was $89 \%$ ), patients with GFR 1-1.49 ml/s (red line, the 10 -year renal survival was $85 \%$ ), patients with GFR $0.5-0.99 \mathrm{ml} / \mathrm{s}$ (green line, the 10 -year renal survival was $50 \%) . \mathrm{P}<0.001$.

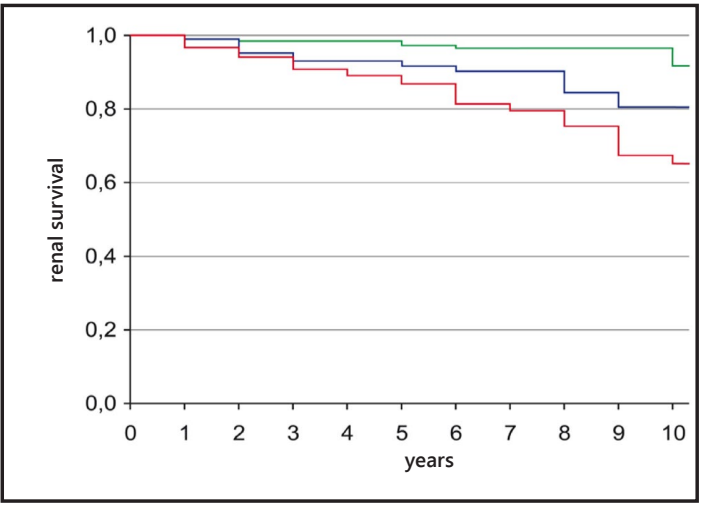

Fig. 4. Kaplan-Meier curves of survival according to the input proteinuria: < 1g/day (green line, the 10year renal survival was $92 \%$ ), < 2g/day (blue line, the 10 -year renal survival was $81 \%$ ) and $>2 \mathrm{~g} /$ day (red line, the 10-year renal survival was $65 \%$ ); $\mathrm{P}<$ 0.001 .

found significantly better renal survival in patients with proteinuria $<1 \mathrm{~g} /$ day compared to patients with higher proteinuria (Figure 5).

Patients with normal renal function and proteinuria $<1 \mathrm{~g}$ /day showed significantly better renal survival compared to patients with normal renal parametres and proteinuria $\geq$ $1 \mathrm{~g} /$ day (Figure 6).

In our study of IgAN patients we evaluated the progression of renal function according to the Bartosik's formula [3] and we compared it with real progression of renal function assessed by GFR at the end of the follow up. The Toronto (Bartosik's) formula uses average mean arterial blood pressure and proteinuria during the first 2 years of follow-up to predict the subsequent slope of estimated GFR [3]. The analysis of the progression of renal function 


\section{Kidney \\ Blood Pressure Research}

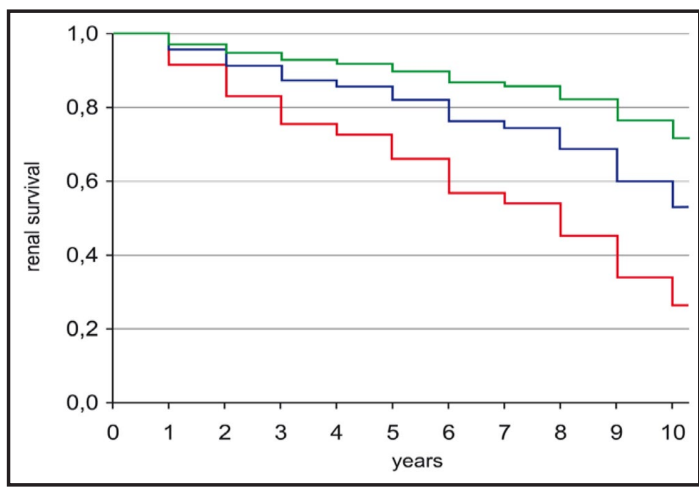

Fig. 5. Kaplan-Meier curves of survival according to GFR $<1 \mathrm{ml} / \mathrm{s}$ and different levels of the input proteinuria: < 1g/day (green line, the 10-year renal survival was $77 \%$ ), $\geq 1 \mathrm{~g} /$ day and $<2 \mathrm{~g} /$ day (blue line, the 10 -year renal survival was $59 \%$ ) and $>2 \mathrm{~g} /$ day (red line, the 10-year renal survival was $35 \%$ ); $\mathrm{P}<0.001$.

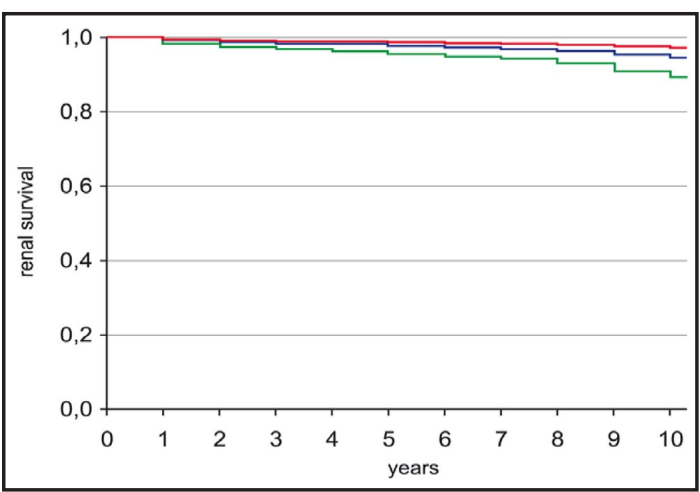

Fig. 6. Kaplan-Meier curves of survival according to GFR $>1.5 \mathrm{ml} / \mathrm{s}$ and different levels of the input proteinuria: $<1 \mathrm{~g} /$ day (red line, the 10 -year renal survival was $98 \%$ ), $\geq 1 \mathrm{~g} /$ day and $<2 \mathrm{~g}$ /day (blue line, the 10 -year renal survival was $95 \%$ ) and $>2 \mathrm{~g} /$ day (green line, the 10-year renal survival was $91 \%$ ); $\mathrm{P}<0.001$.

according to Bartosik's formula was performed in 516 patients with IgAN at the end of the follow up (due to missing some data in 4 patients).

In our group of IgAN patients, the progression of renal function was assessed due to GFR (with the range $1,14 \mathrm{ml} / \mathrm{s}$ for men and $0,9 \mathrm{ml} / \mathrm{s}$ for women). Subsequently, the comparison with the prediction of the progression of renal function assessed according to Bartosik's formula was evaluated using the analysis of the dependence in accordance with McNemar's test with these results: progression of renal function due to Bartosik's formula at the end of the follow up vs. progression of renal function appraised due to GFR at the end of the follow up (with the range 1,14 ml/s for men and 0,9 ml/s for women): p-value: McNemar: 0,072.

In conclusion, we did not find the significant difference between predicted progression of renal function due to Bartosik's formula and real progression of renal parametres assessed by above mentioned GFR at the end of the follow up in our group of IgAN patients.

In our extensive study of 520 Czech IgAN patients with median follow up of six years we assessed not only the risk factors affecting the progression of IgAN and differences among Czech nephrology centers but also the 10-year actuarial renal survival of Czech IgAN patients, $\mathrm{KM}$ curves of renal survival according the different risk factors, assessment of median slope of GFR in the Czech Republic and comparison with other countries. In addition, we validated Toronto Bartosik's formula to predict the prognosis of IgAN patients.

\section{Discussion}

Our study shows the long-term assessment of the largest cohort of IgAN patients in the Czech Republic (population 10.3 million). The group of 520 IgAN patients with median follow up of six years enables to assess and compare the most important risk factors at presentation affecting long-standing prognosis of the disease.

We ascertained the worldwide known risk factors for the progression of renal function of nephropathies, such as proteinuria, hypertension and the lower GFR at the time of the diagnosis [1, 2, 5-10].

In our group of IgAN patients, the overall 10 -year renal survival was $77.1 \%$ which is comparable to previous published evidence (77.8 \% [6], $79.8 \%$ [8], $83 \%$ [7], $84 \%$ [11], $84.3 \%$ [1], $85 \%$ [12]). The geographic variability in the long-standing outcome of IgAN is 


\section{Kidney Blood Pressure Research}

well known with 10-year renal survival ranging from $93.3 \%$ in Helsinki to $61.4 \%$ in Toronto [6]. The geographic variability might be influenced by genetic factors [13], additional environmental factors, eating habits or by different local medical guidelines for screening and treatment of the disease [13].

In our study of IgAN patients median slope of $\mathrm{CrCl}$ was $-1 \mathrm{ml} / \mathrm{min} / 1.73 \mathrm{~m}^{2} /$ year which is comparable to median slope of $\mathrm{CrCl}$ in Helsinki, in Finland $\left(-1.24 \mathrm{ml} / \mathrm{min} / 1.73 \mathrm{~m}^{2} /\right.$ year $)$ [6]. On the contrary other countries showed unfavourable median slope of $\mathrm{CrCl}(-2.95 \mathrm{ml} /$ $\mathrm{min} / 1.73 \mathrm{~m}^{2} /$ year in Sydney, in Australia; - $3.46 \mathrm{ml} / \mathrm{min} / 1.73 \mathrm{~m}^{2} /$ year in Glasgow, UK; - 3.99 $\mathrm{ml} / \mathrm{min} / 1.73 \mathrm{~m}^{2} /$ year in Toronto, in Canada) [6].

In above mentioned study [6] patients from Helsinki and Sydney presented with milder forms of disease with preserved renal function $(\mathrm{CrCl}>75 \mathrm{ml} / \mathrm{min})$ and lower proteinuria $(<0.5 \mathrm{~g} /$ day) compared to patients from Glasgow and Toronto. Finnish patients originated mostly from large army, employment and driving licence screening programmes. Liberal biopsy practice in subjects with suspected nephropaties was noted in Finland and also in Sydney while patients in Toronto and Glasgow undergo renal biopsy in case of heavy proteinuria $(>1 \mathrm{~g} / 24 \mathrm{~h})$ or renal failure [6]. These results correspond with higher biopsy rate in Finland (176 p.m.p./year) [14] and in Australia (215 p.m.p./year) [15] and lower biopsy rate in Scotland (126.3 p.m.p./year) [16, 17]. The biopsy rate in the Czech Republic increased significantly from 44.1 p.m.p./year in 1994 to 58.2 p.m.p./year in 2001 and to 61.6 p.m.p./ year in 2011 [4]. We realize that we used two values of $\mathrm{CrCl}$ (initial and final) to calculate slope of $\mathrm{CrCl}$ compared to minimal 3 mean values in above mentioned publication [6].

In the Czech Republic, we also noticed different renal survival of IgAN patients the overall 10-year renal survival in the General Teaching Hospital in Prague was $64.5 \%$ compared to the overall 10-year renal survival in other Czech nephrology centers with 88.3 $\%)$ which might be influenced by significant differences in the distribution of age $(\mathrm{P}<0.01)$ and GFR $(P<0.01)$ among Prague center and other Czech nephrology centers. We did not find other significant differences in the distribution of gender, hypertension or proteinuria. We noted significantly more patients $>50$ years old in the General Teaching Hospital in Prague $(\mathrm{P}<0.01)$ with significantly more patients with progressive renal insufficiency $(55 \%$ of patients with $\mathrm{CrCl}<0.99 \mathrm{ml} / \mathrm{s}, 17 \%$ of patients in the group with $\mathrm{CrCl}>1.5 \mathrm{ml} / \mathrm{s}$; significant differences in mean $\mathrm{CrCl}: 0.99 \mathrm{ml} / \mathrm{s}$ in patients above 50 years compared to mean $\mathrm{CrCl} 1,36$ $\mathrm{ml} / \mathrm{s}$ in patients below 50 years).

We detected higher number of patients (130 patients) from Prague center in the group with $\mathrm{CrCl}<0,99 \mathrm{ml} / \mathrm{s}$ compared to patients from other Czech nephrology centers (49 patients) and in this group with $\mathrm{CrCl}<0,99 \mathrm{ml} / \mathrm{s}$ also mean level of $\mathrm{CrCl}$ in Prague center $0.58 \mathrm{ml} / \mathrm{s}$ was significantly worse compared to other Czech nephrology centers with $\mathrm{CrCl}$ $0.7 \mathrm{ml} / \mathrm{s}(\mathrm{P}<0.01)$. The distribution of hypertension and proteinuria was not significantly different in the group with $\mathrm{CrCl}<0,99 \mathrm{ml} / \mathrm{s}$ and differences in renal survival are supposed to be caused by worse GFR in older patients. However, higher risk patients with more serious clinical and laboratory findings are concentrated in our Department of Nephrology in Prague where most of the renal biopsies from native kidneys are performed in the Czech Republic (approximately 200 renal biopsies from native kidneys in a year). The higher number of risk patients is supposed to be the cause of faster progression of renal function decline with worse renal survival.

In our study of 520 Czech IgAN patients, 215 patients (41.3\%) were treated by immunossupressive regimen. Unfortunately, we know the specific type of immunossupression only in Prague center (with 192 patients in total), 112 patients (58.3\%) used corticosteroids (34 patients received corticosteroids alone and 85 patients corticosteroids with immunosuppression), 69 patients cyclophosphamide (35.9\%), 11 patients azathioprine (5.7 $\%), 5$ patients cyclosporine (2.6\%). We did not assess the influence of immunossupressive treatment on the prognosis of IgAN patients.

Recent published reports did not ascertain the impact of gender on the progression of IgAN [18]. Geddes CC et al. [6] showed a higher male : female ratio for IgAN patients in Glasgow (4.6) compared to other centers (1.8 in Toronto; 1.7 in Helsinki and 1.5 in Sydney) 


\section{Kidney \\ Blood Pressure Research}

but they did not demonstrate the differences in renal survival or slope $\mathrm{CrCl}$ between males and females and suggested the same outcome for males and females. In Czech IgAN patients we found out male : female ratio 2.2 and we also excluded the significant effect of gender on renal survival of IgAN patients. Contrary to these results, in Japan and other Asian countries $[1,7-9,19-21]$ women overwhelmed to men which indicated that genetic and ethnic factors might be related to gender distribution of IgAN.

Previous published studies did not show the influence of age on renal survival. In our study, Cox hazards proportional model did not confirm the impact of age on renal survival. We found out the 10- year actuarial renal survival in patients younger than 50 years $78 \%$ in comparison with $74 \%$ in patients $\geq 50$ years, however the result is non-significant ( $\mathrm{P}$ 0.514). As well as the dependence of delta GFR (GFR at the end minus GFR at presentation) on age was not ascertained. By way of contrast, Geddes CC et al. [6] and Radford et al. [22] demonstrated protective effect of advancing age on the slope of $\mathrm{CrCl}$ and the risk of ESRD.

Due to usually asymptomatic clinical course of IgAN presented frequently by miscellaneous urinalysis, the most common primary glomerulonephritis is often diagnosed in progressive level of renal insufficiency with hypertension and severe prognosis. In our study, the highest number of patients with ESRD (75\%, 48 patients of the whole group) was assessed in the group of patients with input GFR $<0.99 \mathrm{ml} / \mathrm{s}$. Our previous study showed that patients with macroscopic hematuria and earlier onset of the disease showed favourable prognosis [2]. Other study indicated [1] that more recently diagnosed patients with milder disease at the time of renal biopsy showed a better overall prognosis.

\section{Conclusion}

We assessed long term renal survival and risk factors associated with prognosis in Czech IgAN patients. We found the overall 10-year renal survival $77.1 \%$ in our group of IgAN patients. Hypertension, higher proteinuria $(>1 \mathrm{~g} / \mathrm{d})$, lower GFR at the time of the diagnosis were independent risk factors affecting renal survival in Czech IgAN patients. We validated Toronto (Bartosik's) formula in our cohort of Czech IgAN patients.

\section{Disclosure Statement}

None declared.

\section{Acknowledgements}

The authors thank all colleagues from the participating renal units for supplying the requested data. All authors read and approved the final manuscript. The report was supported by the grant PRVOUK-P25/LF1/2.

\section{References}

$>1$ Moriyama T, Tanaka K, Iwasaki C, Oshima Y, Ochi A, Kataoka H, Itabashi M, Takei T, Uchida K, Nitta K: Prognosis in IgA nephropathy: 30-year analysis of 1,012 patients at a single center in Japan. PLoS One 2014;9:e91756.

2 Maixnerova D,Bauerova L, Skibova J, Rysava R, Reiterova J, Merta M, Honsova E, Tesar V: The retrospective analysis of 343 Czech patiens with IgA nephropathy - one centre experience. Nephrol Dial Transplant 2012;27:1492-1498.

-3 Bartosik LP, Lajoie G, Sugar L, Cattran DC: Predicting progression in IgA nephropathy. Am J Kidney Dis 2001;38:728-735. 


\section{Kidney \\ Blood Pressure Research}

4 Maixnerova D, Jancova E, Skibova J, Rysava R, Rychlik I, Viklicky O, Merta M, Kolsky A, Reiterova J, Neprasova M, Kidorova J, Honsova E, Tesar V: Nationwide biopsy survey of renal diseases in the Czech Republic during the years 1994-2011. J Nephrol 2014, in press.

5 Reich HN, Troyanov S, Scholey JW, Cattran DC: Remission of proteinuria improves prognosis in IgA nephropathy. J Am Soc Nephrol 2007;18:3177-3183.

-6 Geddes CC, Rauta V, Gronhagen-Riska C, Bartosik LP, Jardine AG, Ibels LS, Pei Y, Cattran DC: A tricontinental view of IgA nephropathy. Nephrol Dial Transplant 2003;18:1541-1548.

7 Le W, Liang S, Hu Y, Deng K, Bao H, Zeng C, Liu Z: Long-term renal survival and related risk factors in patients with IgA nephropathy: results from a cohort of 1155 cases in a Chinese adult population. Nephrol Dial Transplant 2012;27:1479-1485.

-8 Lee H, Kim DK, Oh KH, Joo KW, Kim YS, Chae DW, Kim S, Chin HJ: Mortality of IgA nephropathy patients: a single center experience over 30 years. PLOS One 2012;7:e51225.

-9 Katafuchi R, Ninomiya T, Nagata M, Mitsuki K, Hiraoka H: Validation study of Oxford classification of IgA nephropathy: The significance of extracapillary proliferation. Clin J Am Soc Nephrol 2011;6:2806-2813.

10 Alamartine E, Sauron C, Laurent B, Sury A, Seffert A, Mariat C: The use of Oxford classification of IgA nephropathy to predict renal survival. Clin J Am Soc Nephrol 2011;6:2384-2388.

11 Alamartine E, Sabatier JC, Guerin C, Berliet JM, Berthoux F: Prognostic factors in mesangial IgA glomerulonephritis: an extensive study with univariate and multivariate analysis. Am J Kidney Dis 1991;18:12-19.

12 Koyama A, Igarashi M, Kobayashi M: Coworkers of the research group on progressive renal disease. Natural history and risk factors for immunoglobulin A nephropathy in Japan. Am J Kidney Dis 1997;29:526-532.

13 Kiryluk K, Li Y, Sanna-Cherchi S, Rohanizadegan M, Suzuki H, Eitner F, Snyder HJ, Choi M, Hou P, Scolari F, Izzi C, Gigante M, Gesualdo L, Savoldi S, Amoroso A, Cusi D, Zamboli P, Julian BA, Novak J, Wyatt RJ, Mucha K, Perola M, Kristiansson K, Viktorin A, Magnusson PK, Thorleifsson G, Thorsteinsdottir U, Stefansson K, Boland A, Metzger M, Thibaudin L, Wanner C, Jager KJ, Goto S, Maixnerova D, Karnib HH, Nagy J, Panzer U, Xie J, Chen N, Tesar V, Narita I, Berthoux F, Floege J, Stengel B, Zhang H, Lifton RP, Gharavi AG: Geographic differences in genetic susceptibility to IgA nephropathy:GWAS replication study and geospatial risk analysis. PLoS Genet 2012;8:e1002765.

14 Wirta O, Mustonen J, Helin H, Pasternack A: Incidence of biopsy proven glomerulonephritis. Nephrol Dial Transplant 2008;23:193-200.

15 Briganti EM, Dowling J, Finlay M, Hill PA, Jones CL, Kincaid-Smith PS, Sinclair R, McNeil JJ, Atkins RC: The incidence of biopsy-proven glomerulonephritis in Australia. Nephrol Dial Transplant 2001;16:1364-1367.

16 McQuarrie EP, Mackinnon B, Young B, Yeoman L, Stewart G, Fleming S, Robertson S, Simpson K, Fox J, Geddes CC; Scottish Renal Biopsy Registry: Centre variation in incidence, indication and diagnosis of adult native renal biopsy in Scotland. Nephrol Dial Transplant 2009;24:1524-1528.

17 McGrogan A, Franssen CF, de Vries CS: The incidence of primary glomerulonephritis worldwide: a systematic review of the literature. Nephrol Dial Transplant 2011;26:414-430.

18 Cattran DC, Reich HN, Beanlands HJ, Miller JA, Scholey JW, Troyanov S for the Genes, Gender and Glomerulonephritis Group: The impact of sex in primary glomerulonephritis. Nephrol Dial Transplant 2008;23:2247-2253.

19 Miura N, Imai H, Kikuchi S, Hayashi S, Endoh M, Kawamura T, Tomino Y, Moriwaki K, Kiyomoto H, Kohagura K, Nakazawa E, Kusano E, Mochizuki T, Nomura S, Sasaki T, Kashihara N, Soma J, Tomo T, Nakabayashi I, Yoshida M, Watanabe T: Tonsillectomy and steroid pulse (TSP) therapy for patients with IgA nephropathy: a nationwide survey of TSP therapy in Japan and an analysis of the predictive factors or resistence to TSP therapy. Clin Exp Nephrol 2009;13:460-466.

20 Moriyama T, Suzuki K, Sugiura H, Itabashi M, Tsukada M, Takei T, Koike M, Uchida K, Horita S, Taneda S, Honda K, Nitta K: Frequency of renal disease in Japan: An analysis of 2.404 renal biopsies at a single center. Nephron Clin Pract 2010;115:c227-236.

21 Komatsu H, Fujimoto S, Hara S, Fukuda A, Fukudome K, Yamada K, Sato Y, Kitamura K: Recent therapeutic strategies improve renal outcome in patients with IgA nephropathy. Am J Nephrol 2009;30:19-25.

-22 Radford MG Jr, Donadio JV Jr, Bergstralh EJ: Predicting renal outcome in IgA nephropathy. J Am Soc Nephrol 1997;8:199-207. 